\title{
Cost-consequence analysis of fluticasone furoate/vilanterol for asthma management in Spain: an analysis based on the Salford Lung Study in asthma
}

\author{
Laura Amanda Vallejo-Aparicio ${ }^{1}$. Jesús Molina ${ }^{2} \cdot$ Iñigo Ojanguren ${ }^{3,4}$ - Ana Viejo Casas $^{5}$ - Alicia Huerta ${ }^{1}$. \\ Henrik Svedsater ${ }^{6}$
}

Received: 3 December 2018 / Accepted: 9 August 2019 / Published online: 23 September 2019

(c) The Author(s) 2019

\begin{abstract}
Objectives The Salford Lung Study in asthma (SLS asthma) is a 12-month, open-label randomised clinical trial comparing clinical effectiveness of initiating once-daily inhaled combination of fluticasone furoate/vilanterol (FF/VI) 184/22 mcg or $92 / 22 \mathrm{mcg}$, with continuing optimized usual care (UC) with inhaled corticosteroids (ICS) alone, or in combination with a long-acting $\beta 2$-agonist (ICS/LABA), in asthmatic patients followed in primary care in the UK. The objective of the analysis is to estimate the economic impact of these results when applied in Spain.

Methods A 1-year cost-consequence model was populated with SLS asthma, adopting the Spanish National Health System (NHS) perspective. 775,900 of diagnosed asthmatic patients $\geq 18$ years old currently managed with UC in Spain were included in the analysis. Effectiveness data included the percentage of patients per Asthma Control Test (ACT) category at 24 and 52 weeks from SLS asthma. Direct costs (pharmacological and per ACT category) were estimated from Spanish public sources and literature $(€, 2018)$. Base case analysis assumed an increased use of FF/VI from 10 to $20 \%$ within 1 year. One-way sensitivity analyses were performed.

Results Within the 775,900 asthmatic patients analysed, substitution of UC with FF/VI was associated with reduced costs due to ACT improvement, leading to potential total annual savings of $€ 4,927,672$. Sensitivity analyses ranged from $€ 6,012,975$ to $€ 14,783,015$ cost savings associated with FF/VI. An analysis considering patients only on ICS/LABA showed potential cost savings of $€ 8,207,448$.

Conclusions The improved asthma control for FF/VI compared with UC observed in SLS asthma could be translated into potential savings for the Spanish NHS. These results may be useful for decision makers.
\end{abstract}

Keywords Asthma $\cdot$ Fluticasone furoate/vilanterol $\cdot$ Salford Lung Study $\cdot$ Costs $\cdot$ Corticosteroids $\cdot$ Control

JEL Classification I18 $\cdot$ H61

At the time of this work, Alicia Huerta was an employee of GlaxoSmithKline plc.

Laura Amanda Vallejo-Aparicio

laura.a.vallejo@gsk.com

1 Market Access, GSK (GlaxoSmithKline), Madrid, Spain

2 Centro de Salud Francia, Fuenlabrada, Madrid, Spain

3 Servicio de Neumología, Hospital Universitario Vall d'Hebron, Barcelona, Spain

4 Centro de Investigación en Red de Enfermedades Respiratorias (CIBERES), Instituto de Salud Carlos III (ISCIII), Barcelona, Spain

5 Centro de Salud Pisueña Cayon, Cantabria, Spain

6 Value Evidence and Outcomes, GSK, Brentford, UK

\section{Introduction}

Asthma is a common chronic inflammatory disorder of the airways that causes recurrent episodes of breathlessness, chest tightness and coughing [1]. It is one of the most common respiratory conditions in Europe and the prevalence is increasing. Results of the European Community Respiratory Health Survey showed large geographical differences in the prevalence of asthma [2]. The estimated prevalence of asthma in Spain is 4.90\% [3] and is associated with a significant economic burden. It generates high annual costs to the Spanish National Health System (NHS). In Spain in 2016, a total of 23,125 hospital discharges and a total of 134,640 stays were caused by asthma [4]. The total annual costs of 
asthma are estimated to be $€ 3022$ million for patients with asthma diagnosis and the average total direct annual costs of an asthmatic patient have been estimated to reach $€ 1533$ [5]. Indirect costs associated with asthma are also considerable and are mainly due to loss of productivity resulting from absenteeism (lost work and school days) and presenteeism (self-reported impairment at work) [6]. Therefore, the availability and use of healthcare interventions that may contribute to reduce not only the clinical but also the economic burden of the disease seem crucial.

The main goal of asthma management is to achieve and maintain symptom control and minimise the future risk of exacerbations [1]. Despite the availability of effective therapies, several studies show that more than half of the asthmatic patients suffer from suboptimal control [6, 7] and results of the European REALISE study observed that only $20.1 \%$ of patients had controlled asthma [8]. Poorly controlled asthma is also associated with a reduction of patients' health-related quality of life and with substantial healthcare resource use [9].

Nowadays, both international and national guidelines for asthma management $[1,10]$ are mainly based on efficacy randomised controlled trials with usually restrictive patient inclusion/exclusion criteria and this makes it difficult to extrapolate the results to everyday clinical practice. Therefore, there is a need for randomised controlled trials that are closer to usual clinical practice to assist clinicians and healthcare providers in their asthma-related decision-making processes.

The Salford Lung Study (SLS) in asthma (NCT01706198) is a phase III, multicentre, open-label, randomised controlled trial. The primary objective of which was to compare the effectiveness of initiating treatment with the once-daily combination of fluticasone furoate and vilanterol [FF/VI, 184/22 mcg and 92/22 mcg, GlaxoSmithKline, Brentford, London, United Kingdom (UK)] with usual asthma maintenance therapy over a 52-week period on asthma control and safety. The study was conducted in 74 primary care centres in Salford and South Manchester, UK, between 2012 and 2016, in a population intended to be representative of everyday clinical practice. Patients had a general practitioner's diagnosis of symptomatic asthma (without need for spirometry) and were managed by their own primary care team. In this line, practitioners chose the appropriate therapy according to their clinical opinion within the usual care (UC) arm and subjects were randomly allocated to FF/VI or UC and thereby treatments were dispensed by community pharmacies in the usual way [11].

Results of this study showed that significantly more patients initiating treatment with FF/VI were considered responders compared to patients continuing with UC. In the FF/VI group, $71 \%$ patients achieved a relevant response vs $56 \%$ in the usual care group (\%; OR $2.00 ; 95 \%$ CI 1.70 ,
2.34; $p<0.001$ ), in the primary effectiveness analysis (PEA) population, a subgroup of the Intention-to-treat (ITT) population who had an Asthma Control Test (ACT) score less than 20. Response was defined as patients who achieved at week 24 an ACT total score of 20 or greater (indicating well-controlled asthma) or an increase of 3 points (the minimal clinically important difference for ACT) in ACT total score from baseline. The difference in ACT response between the FF/VI and UC groups was consistent over the 52-week period. These results were also achieved in a subset patient population for whom a combination of inhaled corticosteroids with a long-acting $\beta 2$-agonist (ICS/LABA) was intended as UC [11].

To maximize the benefits of healthcare spending, economic evaluation is becoming increasingly relevant in health care decision making for resource allocation. Studies addressing the economic consequences of asthma maintenance treatments are needed to inform decision-making processes. In this sense, the objective of this analysis is to estimate the economic consequences of substitution of UC by FF/VI on the Spanish healthcare budget when applying the SLS asthma results in an everyday clinical practice Spanish population.

\section{Materials and methods}

A cost-consequence economic model was developed in Excel and populated with the SLS Asthma results and Spanish data. A 1-year time horizon was selected, in alignment with the length of the SLS Asthma study duration, and the analysis was performed from the Spanish National Healthcare System (NHS) perspective. The model estimated the economic consequences of the current scenario, and these results were compared to a hypothetical alternative scenario in which the market shares or uses of FF/VI and UC had changed.

The analysis was performed following the recommendations of international and Spanish guidelines for economic evaluation [12-14]. All assumptions made for the analysis were validated with a panel of three clinical experts, the authors of this manuscript.

\section{Study comparators}

Treatment comparators were chosen according to the ones evaluated in the SLS Asthma study:

- FF/VI Including both presentations, 92/22 mcg and $184 / 22$ mcg.

- $U C$ Defined as the maintenance treatment of asthma according to the everyday clinical practice. Patients could receive either an ICS alone or in combination with LABA. 


\section{Model structure}

The model estimated the monetary consequences of substitution of UC by FF/VI on the Spanish health care budget when applying the SLS asthma results to the Spanish population. The model structure is shown in Fig. 1. Results were obtained in terms of pharmacological treatment costs and asthma management costs considering two scenarios:

- Current scenario Represented the current usage of FF/ VI 92/22 mcg and 184/22 mcg and UC as observed in the current everyday clinical practice in Spain

- Alternative scenario Represented a hypothetical everyday clinical practice assuming an increase in usage of FF/VI with respect to the current practice.

- Lastly, the model estimated differences in costs between both scenarios.

The reference year chosen for the analysis was 2018 . For that year, the current usage of FF/VI in Spain was estimated to be $10 \%$ with respect to the rest of asthma maintenance treatments available in the market (UC $=90 \%$ ). For the base case analysis, in the alternative scenario, the model assumed an increase of usage of $\mathrm{FF} / \mathrm{VI}$ up to $20 \%(\mathrm{UC}=80 \%)$ to explore the economic consequences of this increase. Other values of usage in the alternative scenario were also explored as part of the deterministic sensitivity analysis to assess the potential impact on the results.

\section{Model inputs}

\section{Population}

The Spanish population was included in alignment with the SLS asthma study inclusion criteria [11]: patients aged $\geq 18$ years, with asthma diagnosis confirmation, who had a regular maintenance inhaler therapy with either ICS or ICS/LABA. Considering these criteria, the number of Spanish patients to be included in the economic model was estimated based on local data [3, 15-17]. Population estimation is detailed in Fig. 2.

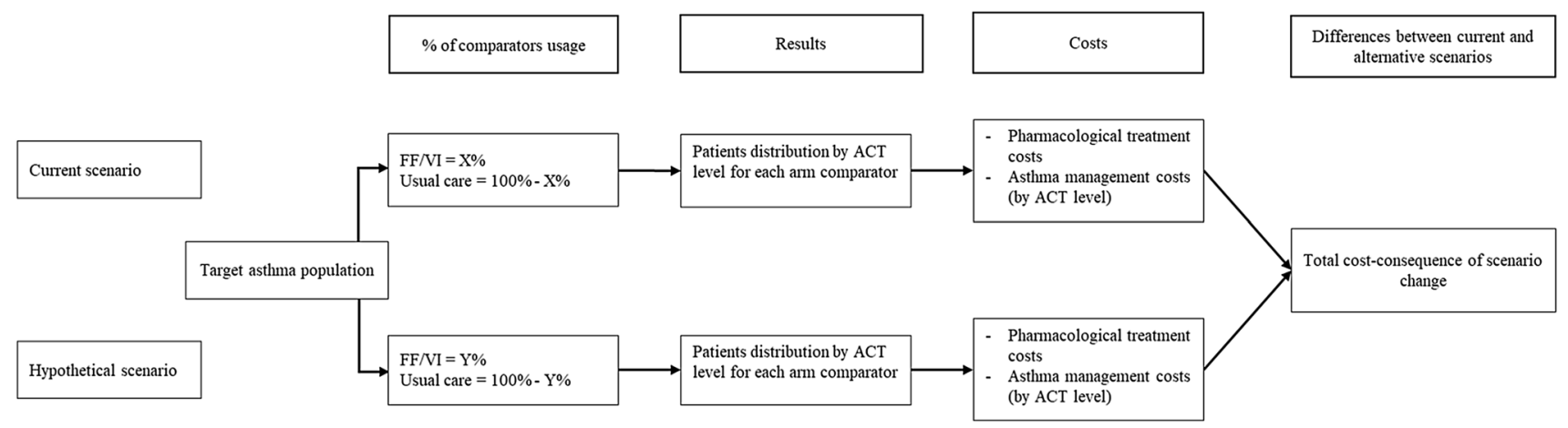

Fig. 1 Economic model structure. FF/VI fluticasone furoate/vilanterol, ACT asthma control test

Fig. 2 Spanish asthmatic target population estimation. ICS inhaled corticosteroid, ICS/ $L A B A$ inhaled corticosteroid/ long-acting beta-agonist

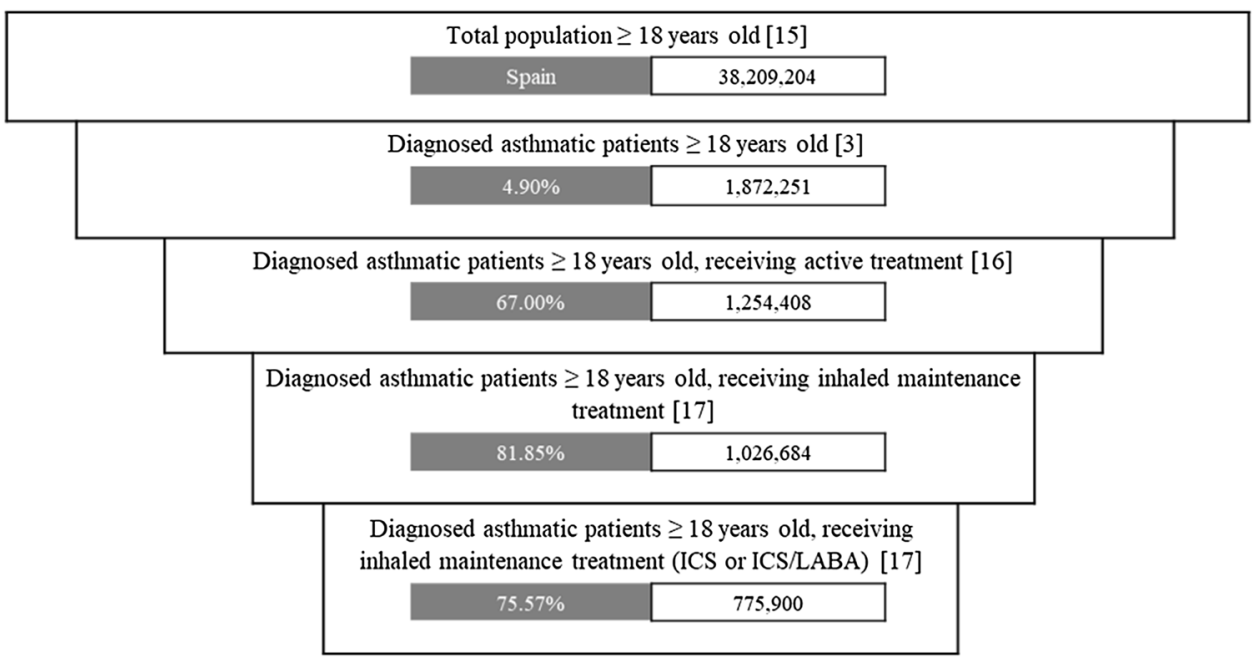




\section{Clinical inputs}

In the SLS asthma study, primary effectiveness endpoint was defined as the percentage of patients to achieve (a) an ACT score of 20 points or greater, or (b) an increase in ACT score from baseline of three points or greater at 24 weeks (termed responders) in the PEA population [defined as the ITT patients with a baseline ACT score less than $20(n=3026)]$ [11]. The mean change from baseline in ACT total score at weeks 12, 24, 40 and 52 was also measured as a secondary endpoint in the ITT population; this enabled us to know the distribution of patients among each ACT category at the different time points [18].

In the present analysis, treatment effect of both comparators on asthma control was incorporated using the patient distribution among the three ACT categories (well controlled, $\geq 20$; partially controlled, 16-19 and uncontrolled $\leq 15$ ) observed during the SLS asthma study in the ITT population ( $n=4233$ ) [18]. It included the patient distribution at
24 weeks for the first 24 weeks of the year and at 52 weeks for the remaining 28 weeks. Results are detailed in Table 1.

\section{Cost inputs}

Asthma management costs Total asthma management costs were estimated based on the distribution of patients among the three ACT categories, as seen in the SLS Asthma (Table 1), multiplied by literature-derived costs per each ACT category. Costs per ACT category were obtained from a published Spanish prospective study of 3-month follow-up of asthmatic patients classified by ACT category that calculated the direct and indirect costs associated with each ACT level. Based on the results of this study, the average annualised direct costs (actualised to 2018) were: $€ 656.90$ for controlled asthma, were $€ 1015.61$ for partially controlled asthma and $€ 1919.01$ for uncontrolled asthma $[19,20]$. Adverse events costs were not included as no differences in serious adverse events were observed between groups [11].
Table 1 Model inputs for base case analysis

\begin{tabular}{|c|c|c|}
\hline Variables & $\begin{array}{l}\text { FF/VI } \\
184 / 22 \mathrm{mcg} \text { and } \\
92 / 22 \mathrm{mcg}\end{array}$ & UC group \\
\hline Monthly drug costs $[17,21]$ & $€ 51.52^{\mathrm{a}}$ & $\begin{array}{l}\mathrm{ICS}=€ 18.75^{\mathrm{b}} \\
\mathrm{ICS} / \mathrm{LABA}=€ 48.25^{\mathrm{b}}\end{array}$ \\
\hline Annual drug costs $(€, 2018)$ & $€ 627.26$ & $€ 557.31$ \\
\hline \multicolumn{3}{|c|}{ Asthma management direct annual costs $(€, 2018)^{\mathrm{c}}[19,20]$} \\
\hline Uncontrolled (ACT score $\leq 15)$ & $€ 656.90$ & \\
\hline Partially controlled (ACT score 16-19) & $€ 1015.61$ & \\
\hline Well-controlled (ACT score $\geq 20$ ) & $€ 656.90$ & \\
\hline Assumed proportion of days covered, $\%$ & 100 & 100 \\
\hline Assumed current uptake, $\%$ & 10 & 90 \\
\hline Assumed new uptake, \% & 20 & 80 \\
\hline \multicolumn{3}{|c|}{ Percentage of subjects in each ACT category (ITT population, $n=4233$ ) [18] } \\
\hline \multicolumn{3}{|l|}{ Baseline } \\
\hline Uncontrolled & $41 \%$ & $41 \%$ \\
\hline Partially controlled & $31 \%$ & $31 \%$ \\
\hline Well controlled & $28 \%$ & $28 \%$ \\
\hline \multicolumn{3}{|l|}{24 weeks } \\
\hline Uncontrolled & $20 \%$ & $29 \%$ \\
\hline Partially controlled & $20 \%$ & $25 \%$ \\
\hline Well controlled & $60 \%$ & $46 \%$ \\
\hline \multicolumn{3}{|l|}{52 weeks } \\
\hline Uncontrolled & $21 \%$ & $30 \%$ \\
\hline Partially controlled & $20 \%$ & $26 \%$ \\
\hline Well controlled & $59 \%$ & $44 \%$ \\
\hline
\end{tabular}

FF/VI fluticasone furoate/vilanterol, ICS inhaled corticosteroid, ICS/LABA inhaled corticosteroid/long-acting beta-agonist, $A C T$ Asthma Control Test, ITT intention-to-treat

${ }^{a}$ Price to public plus VAT of FF/VI 184/22 and 92/22 mcg

${ }^{\mathrm{b}} \mathrm{UC}$ cost calculated as a weighted average drug cost of all available presentations at price to public plus VAT

${ }^{\mathrm{c}}$ Costs annualised at updated to 2018 
Pharmacological costs The model estimated the annual pharmacological costs of each comparator, which were based on monthly treatment costs, calculated as acquisition cost per medication packs delivered at retail pharmacies and expressed as price to public plus value-added tax (PTP + VAT) from the Spanish Ministry of Health Catalogue published in April 2018 [21].

For FF/VI, the monthly cost for both presentations $(184 / 22$ and $92 / 22 \mathrm{mcg}$ ) was established as price per pack from published PTP + VAT [21].

The monthly cost for the UC arm was based on monthly costs of each therapeutic class, ICS and ICS/LABA, and considering the relative market shares for each class as observed in clinical practice in Spain.

According to a market research study performed in the year 2017, the relative market shares within UC applied in this analysis were $91.6 \%$ for ICS/LABA and $8.4 \%$, for ICS [14].

To calculate the monthly costs for the therapeutic groups of ICS and ICS/LABA, all active ingredients, brands and presentations available in Spain for each class as of April 2018 were considered. Cost estimation was based on:

- Relative market shares of each presentation within the therapeutic class in the Spanish market, according to retail data for 2017 [14].

- PTP + VAT of all available presentations, detailed in Table 2 [17].

The ICS/LABA cost was obtained excluding FF/VI from calculations.

Overall UC monthly costs were calculated using the following formula:

UC monthly cost $=\left(\% \mathrm{ICS} \times\left[\left(P_{1} \times W_{1}\right)+\left(P_{2} \times W_{2}\right)+\cdots\right.\right.$

$$
\begin{aligned}
& \left.\left.+\left(P_{n} \times W_{n}\right)\right]\right)+\left(\% \mathrm{ICS} / \mathrm{LABA} \times\left[\left(P_{1^{\prime}} \times W_{1^{\prime}}\right)\right.\right. \\
& \left.\left.+\left(P_{2^{\prime}} \times W_{2^{\prime}}\right)+\cdots+\left(P_{n^{\prime}} \times W_{n^{\prime}}\right)\right]\right),
\end{aligned}
$$

where \%ICS is the relative weight of the ICS therapeutic class within $\mathrm{UC}, P_{1}$ is the price of presentation 1 from the ICS therapeutic class, $W_{1}$ is the relative weight of presentation 1 within the ICS therapeutic class, \%ICS/LABA is the relative weight of the ICS/LABA therapeutic class within $\mathrm{UC}, P_{1^{\prime}}$ is the price of presentation 1 from the ICS/LABA therapeutic class, $W_{1}$, is the relative weight of presentation 1 within the ICS/LABA therapeutic class.

In the base case analysis, complete patient compliance with both treatment arms was assumed for pharmacological cost calculation, meaning a proportion of days covered (PDC) with study medications of $100 \%$. This value was modified to assess potential impact on study results as part of the deterministic sensitivity analyses that are detailed in Table 3.

Main assumptions, variables and inputs used for the base case analysis in the economic model are summarised in Table 1.

\section{Results reporting}

Results were expressed as cost differences of both scenarios [in euros $(€)$ for 2018] obtained with the following formula:

$$
\begin{aligned}
\text { Cost }- \text { consequence }= & \left(\mathrm{Pcosts}_{\mathrm{CS}}+\mathrm{AMcosts}_{\mathrm{CS}}\right) \\
& -\left(\mathrm{Pcosts}_{\mathrm{AS}}+\mathrm{AMcosts}_{\mathrm{AS}}\right) \\
= & \Delta €,
\end{aligned}
$$

where Pcosts is the pharmacological costs, AMcosts is the asthma management costs, CS is the current scenario, and AS is the alternative scenario.

\section{Sensitivity analyses}

To minimise the impact of uncertainty and to determine the robustness of the results, different scenarios from the base case were explored:

- It was observed that the use of ICS/LABA as maintenance treatment for asthmatic patients is widespread in Spain. To analyse the potential impact on the results of the ICS/LABA use, the effectiveness results of the ICS/ LABA subgroup of the ITT population were applied as clinical inputs.

- In the SLS asthma, data were collected for the PEA population $(n=3026)$, defined as all ITT included subjects with an ACT score of less than 20 points at baseline. Therefore, an additional scenario was analysed using the patient's distribution among the ACT categories observed in the PEA population to investigate the impact in asthma management costs compared with the base case results.

- Another alternative scenario analysis was performed from the society perspective, including loss of productivity costs by ACT level, extracted from the published literature. Annualised asthma management indirect costs and actualised to 2018 were $€ 17.23$ for well-controlled asthma, $€ 49.92$ for partially controlled and $€ 540.71$ for uncontrolled asthma [19, 20].

- To explore the results in a longer term, a 3-year time horizon was selected, where year 1 base case scenario was compared with a $20 \%$ of FF/VI use in the alternative scenario. For the 2 nd year, base case was compared with a $25 \%$ use of FF/VI and for the 3rd year vs a $30 \%$ use. Differential treatment effects between comparators from the SLS Asthma study were maintained during the whole time horizon. Following Spanish guidelines recommen- 
Table 2 Detail of retail prices used for the UC arm monthly cost estimation

\begin{tabular}{|c|c|c|c|c|}
\hline Active ingredient & Brand name & Strength and pack size & $\begin{array}{l}\text { Cost per pack } \\
\text { PTP + VAT }(€)[21]\end{array}$ & $\begin{array}{l}\text { Market } \\
\text { shares (\%) } \\
{[17]}\end{array}$ \\
\hline \multicolumn{5}{|l|}{ Inhaled corticosteroids (ICS) } \\
\hline \multirow[t]{5}{*}{ Fluticasone propionate } & \multirow[t]{2}{*}{ Flixotide Accuhaler ${ }^{\circledR}$} & $500 \mathrm{mcg} \times 60$ doses & $€ 31.47$ & \multirow[t]{5}{*}{20} \\
\hline & & $100 \mathrm{mcg} \times 60$ doses & $€ 11.43$ & \\
\hline & \multirow[t]{2}{*}{ Flixotide $^{\circledR}$} & $250 \mathrm{mcg} \times 120$ doses & $€ 31.47$ & \\
\hline & & $50 \mathrm{mcg} \times 120$ doses & $€ 11.43$ & \\
\hline & Fluticasona Cipla $^{\circledR}$ & $125 \mathrm{mcg} \times 120$ doses & $€ 15.74$ & \\
\hline \multirow[t]{11}{*}{ Budesonide } & \multirow[t]{3}{*}{ Pulmicort Turbuhaler ${ }^{\circledR}$} & $200 \mathrm{mcg} \times 100$ doses & $€ 13.16$ & \multirow[t]{11}{*}{70} \\
\hline & & $100 \mathrm{mcg} \times 200$ doses & $€ 13.16$ & \\
\hline & & $400 \mathrm{mcg} \times 100$ doses & $€ 26.32$ & \\
\hline & \multirow[t]{3}{*}{ Budesonide Easyhaler ${ }^{\circledR}$} & $200 \mathrm{mcg} \times 200$ doses & $€ 26.32$ & \\
\hline & & $100 \mathrm{mcg} \times 200$ doses & $€ 13.16$ & \\
\hline & & $400 \mathrm{mcg} \times 100$ doses & $€ 26.32$ & \\
\hline & \multirow[t]{3}{*}{ Budesonide Pulmictan ${ }^{\circledR}$} & $50 \mathrm{mcg} \times 200$ doses & $€ 7.56$ & \\
\hline & & $200 \mathrm{mcg} \times 100$ doses & $€ 11.11$ & \\
\hline & & $200 \mathrm{mcg} \times 200$ doses & $€ 20.25$ & \\
\hline & \multirow[t]{2}{*}{ Miflonide $^{\circledR}$} & $200 \mathrm{mcg} \times 60$ doses & $€ 7.90$ & \\
\hline & & $400 \mathrm{mcg} \times 60$ doses & $€ 15.80$ & \\
\hline \multirow[t]{2}{*}{ Beclometasone } & Becotide $^{\circledR}$ & $50 \mathrm{mcg} \times 200$ doses & $€ 3.50$ & \multirow[t]{2}{*}{2} \\
\hline & Becloforte $^{\circledR}$ & $250 \mathrm{mcg} \times 200$ doses & $€ 18.98$ & \\
\hline \multirow[t]{2}{*}{ Mometasone furoate } & \multirow[t]{2}{*}{ Asmanex ${ }^{\circledR}$} & $200 \mathrm{mcg} \times 60$ doses & $€ 29.07$ & \multirow[t]{2}{*}{3} \\
\hline & & $400 \mathrm{mcg} \times 60$ doses & $€ 51.14$ & \\
\hline Ciclesonide & Alvesco ${ }^{\circledR}$ & $160 \mathrm{mcg} \times 60$ doses & $€ 32.78$ & 5 \\
\hline \multicolumn{5}{|l|}{ ICS/LABA fixed-dose combinations } \\
\hline \multirow[t]{8}{*}{ Fluticasone propionate/salmeterol } & \multirow[t]{3}{*}{ Seretide $^{\circledR}$} & $25 / 50 \mathrm{mcg} \times 120$ doses & $€ 41.28$ & \multirow[t]{8}{*}{31} \\
\hline & & $25 / 125 \mathrm{mcg} \times 120$ doses & $€ 41.28$ & \\
\hline & & $25 / 250 \mathrm{mcg} \times 120$ doses & $€ 41.28$ & \\
\hline & \multirow[t]{3}{*}{ Seretide Accuhaler ${ }^{\circledR}$} & $50 / 100 \mathrm{mcg} \times 60$ doses & $€ 41.28$ & \\
\hline & & $50 / 250 \mathrm{mcg} \times 60$ doses & $€ 41.28$ & \\
\hline & & $50 / 500 \mathrm{mcg} \times 60$ doses & $€ 41.28$ & \\
\hline & \multirow[t]{2}{*}{ Airflusal Forspiro $^{\circledR}$} & $50 / 250 \mathrm{mcg} \times 60$ doses & $€ 41.28$ & \\
\hline & & $50 / 500 \mathrm{mcg} \times 60$ doses & $€ 41.28$ & \\
\hline \multirow[t]{5}{*}{ Budesonide/formoterol } & \multirow[t]{2}{*}{ Symbicort Turbuhaler ${ }^{\circledR}$} & $80 / 4,5 \mathrm{mcg} \times 120$ doses & $€ 51,39$ & \multirow[t]{5}{*}{44} \\
\hline & & $160 / 4,5 \mathrm{mcg} \times 120$ doses & $€ 51.39$ & \\
\hline & Symbicort Forte Turbuhaler ${ }^{\circledR}$ & $320 / 9 \mathrm{mcg} \times 60$ doses & $€ 51.39$ & \\
\hline & DuoResp Spiromax $^{\circledR}$ & $160 / 4.5 \mathrm{mcg} \times 120$ doses & $€ 51.39$ & \\
\hline & & $320 / 9 \mathrm{mcg} \times 60$ doses & $€ 51.39$ & \\
\hline Beclometasone/formoterol & Foster $^{\circledR}$ & $100 / 6 \mathrm{mcg} \times 120$ doses & $€ 51.52$ & 19 \\
\hline & & $200 / 6 \mathrm{mcg} \times 120$ doses & $€ 51.52$ & \\
\hline & Foster Nexthaler ${ }^{\circledR}$ & $100 / 6 \mathrm{mcg} \times 120$ doses & $€ 51.52$ & \\
\hline & & $200 / 6 \mathrm{mcg} \times 120$ doses & $€ 51.52$ & \\
\hline Fluticasone propionate/formoterol & Flutiform $^{\circledR}$ & $50 / 5 \mathrm{mcg} \times 120$ doses & $€ 32.86$ & 7 \\
\hline & & $125 / 5 \mathrm{mcg} \times 120$ doses & $€ 45.79$ & \\
\hline & & $250 / 10 \mathrm{mcg} \times 120$ doses & $€ 71.81$ & \\
\hline
\end{tabular}

$P T P+V A T$ price to public plus value added tax, ICS inhaled corticosteroid, $L A B A$ long-acting beta-agonists 
Table 3 Deterministic sensitivity and alternative scenario analyses performed

\begin{tabular}{|c|c|c|}
\hline Modified parameters & Base case value/s & Alternative value/s \\
\hline Effectiveness results & ITT population (FF/VI vs ICS and ICS/LABA) [18] & ITT population (FF/VI vs ICS/LABA) [18] \\
\hline Effectiveness results & ITT population (FF/VI vs ICS and ICS/LABA) [18] & PEA population (FF/VI vs ICS and ICS/LABA) [18] \\
\hline Analysis perspective & $\begin{array}{l}\text { Spanish National Healthcare System (only direct costs) } \\
{[19,20]}\end{array}$ & $\begin{array}{l}\text { Society including indirect costs by ACT category: }[19 \text {, } \\
\text { 20] } \\
\text { Uncontrolled: } € 540.71 \\
\text { Partially controlled: } € 49.92 \\
\text { Well controlled: } € 17.23 €\end{array}$ \\
\hline Time horizon & 1 year $[11]$ & $\begin{array}{l}3 \text { years (assuming an increase of usage of FF/VI in each } \\
\text { year) (assumptions) }\end{array}$ \\
\hline $\begin{array}{l}\text { Usage of comparators in } \\
\text { the alternative scenario }\end{array}$ & $\begin{array}{l}\text { FF/VI } 20 \% \\
\text { UC } 80 \% \text { (assumption) }\end{array}$ & $\begin{array}{l}\text { (1) } \mathrm{FF} / \mathrm{VI}=30 \% \\
\mathrm{UC}=70 \% \\
\text { (2) } \mathrm{FF} / \mathrm{VI}=40 \% \\
\mathrm{UC}=60 \% \text { (assumptions) }\end{array}$ \\
\hline Proportion of days covered & $100 \%$ (assumption) & $\begin{array}{l}\text { (1) } 80 \%[10] \\
\text { (2) } 50 \%[22] \\
\text { (3) } 33 \%[23]\end{array}$ \\
\hline
\end{tabular}

dations, a $3 \%$ discount rate was applied to years 2 and 3 [14].

In addition, several one-way deterministic sensitivity analyses were performed by individually modifying selected parameters:

- Percentage of usage of FF/VI in the alternative scenario: in the base case, $10 \%$ of FF/VI usage was compared to $20 \%$ usage in the hypothetical scenario. To explore the economic consequences of a higher increase in usage, the same usage of FF/VI in the base case for the current scenario was compared with an increase of usage of $30 \%$ and $40 \%$ in the alternative scenarios.

- Patient compliance to drug treatments: in an everyday clinical practice, asthmatic patients are not thought to be fully compliant with their medication. Therefore, PDC was modified to $80 \%$ of days covered (average compliance treatment observed in the SLS asthma study), and $50 \%$ and $33 \%$ (based on literature $[22,23]$ ) to analyse the impact of different compliance rates on the results.

All value modifications for the sensitivity and other scenario analyses performed are detailed in Table 3.

\section{Results}

\section{Base case analysis results}

A total of 775,900 asthmatic patients were estimated and included in the model, with the specified calculation methods (Fig. 2). For the base case analysis, an increase of usage of FF/VI in the alternative scenario was associated with:
- Increased drug treatment costs: accounting for an increment of $€ 5,427,249$.

- Decreased asthma management costs: accounting for $€ 10,354,921$ cost savings.

As a result, a substitution of UC with FF/VI up to $20 \%$ could lead to potential total annual cost savings of $€ 4,927,672$ for the Spanish NHS. Cost savings were mainly derived from the ACT improvement when treated with FF/ VI compared with continuing with usual care.

\section{Deterministic sensitivity and scenario analyses results}

Results from all the different analyses, both deterministic and scenario analyses, were shown to be consistent with the base case, demonstrating the robustness of the base case analysis results. Cost savings ranged from $€ 6,012,975$ to $€ 14,783,015$ and are detailed in Fig. 3.

As for the deterministic sensitivity analyses, the modification of the parameter "increase of usage of FF/VI in the alternative scenario" had the highest impact on the results with respect to base case. Prolonging the time horizon to 3 years and varying the rates of use of FF/VI each year caused the highest variability of the results but remained consistent with the base case.

The scenario analysis considering patients on ICS/LABA only showed that potential cost savings increased up to $€ 8,207,448$. In addition, a similar increase in cost savings was observed, when performing the analysis from a societal perspective that included indirect costs due to loss of productivity, with cost savings of $€ 8,723,709$.

Base case and sensitivity analyses results are presented in Table 4. 


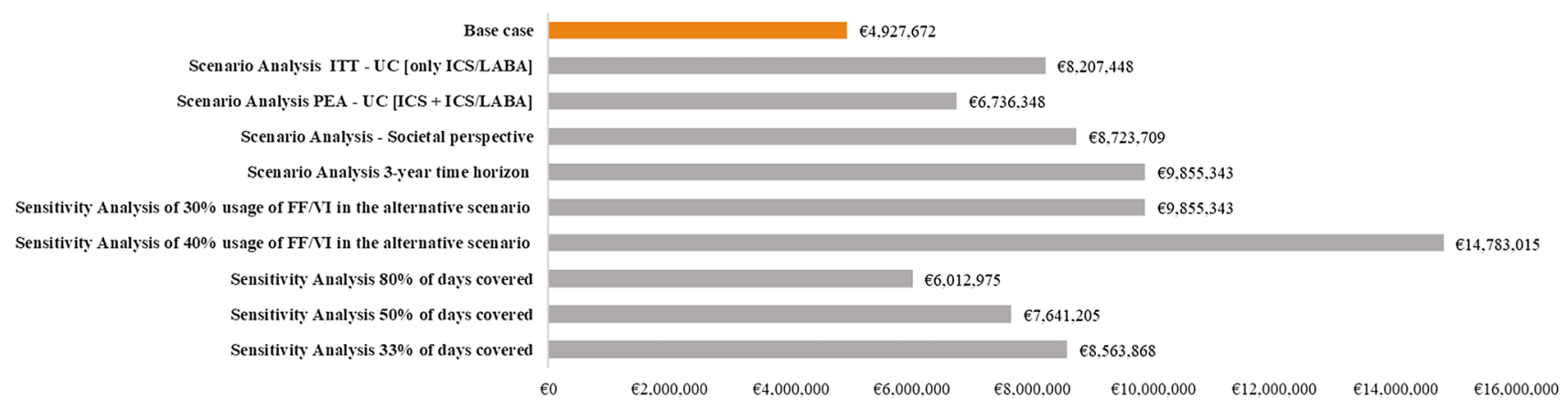

Fig. 3 Potential cost savings of base case, sensitivity and scenario analyses. ITT intention-to-treat, $U C$ usual care, $P E A$ primary effectiveness analysis, ICS inhaled corticosteroid, ICS/LABA inhaled corticosteroid/long-acting beta-agonist

Table 4 Economic model results

\begin{tabular}{llll}
\hline Assessed scenario & Total costs current scenario & $\begin{array}{l}\text { Total costs hypothetical } \\
\text { scenario }\end{array}$ & $\begin{array}{l}\text { Potential cost sav- } \\
\text { ings obtained with } \\
\text { FF/VI }\end{array}$ \\
\hline Base case & & $€ 1,292,588,296$ & $-€ 4,927,672$ \\
ITT population-UC (only ICS/LABA) & $€ 1,297,515,968$ & $€ 1,353,688,953$ & $-€ 8,207,448$ \\
PEA population-UC (ICS and ICS/LABA) & $€ 1,361,896,401$ & $€ 1,374,163,664$ & $-€ 6,736,348$ \\
Societal perspective & $€ 1,380,900,012$ & $€ 1,424,818,887$ & $-€ 8,723,709$ \\
3-year time horizon & $€ 1,433,542,596$ & $€ 3,758,879,953$ & $-€ 9,642,147$ \\
FF/VI usage up to 30\% in the alternative scenario & $€ 3,768,522,100$ & $€ 1,287,660,625$ & $-€ 9,855,343$ \\
FF/VI usage up to 40\% in the alternative scenario & $€ 1,297,515,968$ & $€ 1,282,732,953$ & $-€ 14,783,015$ \\
PDC of $80 \%$ & $€ 1,209,946,109$ & $€ 1,203,933,134$ & $-€ 6,012,975$ \\
PDC of $60 \%$ & $€ 1,078,593,799$ & $€ 1,070,952,594$ & $-€ 7,641,205$ \\
PDC of 33\% & $€ 1,004,160,823$ & $€ 995,596,955$ & $-€ 8,563,868$ \\
\hline
\end{tabular}

\section{Discussion}

The present study revealed that UC with FF/VI in Spanish asthmatic patients could lead to potential total annual savings of $€ 4,927,672$. When the effectiveness results of the ICS/LABA ITT subgroup were used as clinical input data, the cost savings increased up to $€ 8,207,448$. An increase in FF/VI usage among Spanish asthmatic patients could contribute to reduce the total economic burden associated with the management of asthma in Spain.

These results confirmed that the health benefit in terms of asthma control with FF/VI compared with UC seen in the SLS Asthma study could be translated into economic benefits for the Spanish NHS. Despite the increase of drug treatment costs related to the substitution of $\mathrm{UC}$ by FF/ VI, they are compensated by cost savings resulting from a reduction in asthma management costs. These results become particularly relevant to the Spanish current everyday clinical practice, as it is estimated that ICS/LABA fixed-dose combinations are widely used among asthmatic maintenance treatment when compared to ICS alone, with market shares of $91.6 \%$ and $8.4 \%$, respectively. Funding medicines in a sustainable manner is a challenge for health policy in many countries due to scarce resources. Economic evaluation can be used as a tool for healthcare policy decision makers to ensure health resources are allocated efficiently, maximizing patient outcomes.

Thus far, this is the first analysis in Spain estimating the economic impact of an increase in the use of FF/VI for asthma maintenance treatment, based on effectiveness results (SLS asthma). Previous studies performed in Spain had only assessed the cost effectiveness of asthma drug treatments and were based on clinical trials [24-26]. In line with the SLS asthma, a similar analysis was performed applying the clinical data, in terms of COPD exacerbations rate reduction, from the SLS COPD study to the Spanish population. Results from this analysis showed that an increase in usage of FF/VI for maintenance treatment in COPD patients could lead to potential annual total cost savings of $€ 353,622.98$ for the Spanish NHS [27]. Up to now, both SLS Asthma and COPD studies represent the largest effectiveness studies 
conducted in routine clinical practice which may help to support their everyday decision-making processes.

According to guidelines, the long-term goals of disease management are achieving good control of symptoms and maintaining normal activity levels, as well as minimising future risk of exacerbations [1]. Asthma control is a key aspect of disease treatment and a good guide to a reduced risk of exacerbations [28]. Moreover, it is significantly associated with costs and health-related quality of life in Spain and it was observed that costs were higher and health-related quality of life lower, as the level of asthma control decreased [14]. In this sense, the present analysis supports the economic consequences of an improvement in asthma control due to changes in maintenance treatments.

One limitation of this analysis could be related to the distribution of treatments in the UC arm used for cost calculations. Data from the SLS asthma show that the relative weights of $36 \%$ for ICS and $64 \%$ for ICS/LABA at the start of the study differ from the market shares observed in the current clinical everyday practice in Spain, $8.4 \%$ and $91.6 \%$, respectively. These differences could be related to the study development time period, as the SLS asthma study was conducted between 2012 and 2016, and treatment usage trends could have varied between that time and 2018, the reference year for the present analysis. Therefore, to be more representative of the current clinical everyday practice in Spain, it was decided not to use the distribution observed in SLS Asthma.

Additionally, limitations of the data source used to obtain the asthma management costs should be considered. Costs by ACT level were obtained from a 3-month follow-up study conducted in 2013 in Spain and were then annualised and updated with Consumer Price Index (CPI) to 2018 [19, 20] following the recommendations of the guidelines for economic evaluation [12-14]. Nevertheless, up to date, no other sources to obtain asthma management costs by ACT level in Spain are available to be used as an input for the present analysis. Related to this cost data, it should also be mentioned that this observational study also included pharmacological costs as part of the asthma management cost calculation, so it may result in double counting as in the present analysis pharmacological cost has been obtained for both study arms. However, this double counting equally affects both study arms and all scenarios so minimal impact is expected, as the objective of our analysis is to explore if there are differences in asthma control costs between being treated with FF/VI or continuing their usual care treatment.

The patient population of the Salford Lung study had a general practitioner's diagnosis of symptomatic asthma (without the need for spirometry). Although, in Salford, primary care is supported by trained physicians in respiratory, the level of misdiagnosis was not recorded, and it will certainly occur, which could lead to a disease management cost overestimation. Nevertheless, this would equally affect both study arms and both scenarios, as in the previous limitation.

Another limitation that should be mentioned could be related to the adherence to treatments. Good adherence is associated with better asthma control [29]. Due to the lack of local studies about the possible impact of adherence in effectiveness results, the different rates of days covered were only applied to pharmacological costs, both in the base case and the deterministic analyses, where the value of this parameter varied.

In addition, data from a retrospective study showed rates of compliance with asthma treatment of 33\% [23]. In the present analysis for the base case, to estimate the annual costs of the pharmacological treatment, monthly costs were considered assuming that the patient would be totally compliant with their medication during the whole year, meaning a proportion of days covered of 100 . Given that poor adherence to treatment is widespread in asthma, this analysis could be overestimating the true medication-related costs. Therefore, to mitigate the uncertainty of the possible impact of adherence in the results, different values for the proportion of days covered were used as part of the deterministic sensitivity analyses. Lack of adherence to ICS treatments in asthma has been not only associated with poorer clinical outcomes but also with an increase in healthcare resource and associated costs [30].

Despite the above-mentioned limitations, and in addition to the demonstrated clinical effectiveness from the SLS Asthma study, results from this analysis may be useful for evaluators and decision makers in the selection of asthma maintenance treatments in Spain.

\section{Conclusion}

Results from the present study suggest that the improvement in asthma control with FF/VI compared with usual care, including other ICS/LABAs, as maintenance treatment of asthmatic patients in an everyday clinical setting could result in potential cost savings to the Spanish NHS, reducing the associated burden of the disease. In this sense, these results could be considered useful for decision-making processes related to asthma maintenance treatment.

Acknowledgements The authors want to acknowledge Laura Atienza (GSK) for the editorial support in terms of literature review, writing and editing previous versions of this manuscript. GSK makes available anonymized individual participant data and associated documents from interventional clinical studies which evaluate medicines, upon approval of proposals submitted to http://www.clinicalstudydatareq uest.com. To access data for other types of GSK-sponsored research, for study documents without patient-level data and for clinical studies not listed, please submit an enquiry via the website. 
Author contributions All authors made substantial contributions to this study: LAV-A: conception and design, data acquisition, analysis, and interpretation. JM: conception and design, data analysis and interpretation. IO: conception and design, data analysis and interpretation. $\mathrm{AV}$ : conception and design, data analysis and interpretation. AHH: conception and design, data acquisition, data analysis, and interpretation. All authors have critically revised this manuscript for important intellectual content. All authors have approved the final version of the manuscript to be published. All authors agree to being accountable for all aspects of the work in ensuring that questions related to the accuracy or integrity of the work are appropriately investigated and resolved.

Funding This analysis has been performed by GlaxoSmithKline (code HO-18-19245).

\section{Compliance with ethical standards}

Conflict of interest Laura Amanda Vallejo-Aparicio is an employee of GlaxoSmithKlne. Jesús Molina received fees for his involvement in the present analysis, not receiving any payment for writing the manuscript, and has received speaker fees from AstraZeneca, Boehringer Ingelheim, Chiesi, GlaxoSmithKline, Menarini, Novartis, Roche, AstraZeneca and consulting fees form AstraZeneca, Boehringer Ingelheim and GlaxoSmithKline. Iñigo Ojanguren has received fees for his involvement in the present analysis, not receiving any payment for writing the manuscript, speaker fees from Boehringer Ingelheim, Novartis, TEVA, Astrazeneca and consulting fees form GlaxoSmithKline. Ana Viejo received fees for her involvement in the present analysis, not receiving any payment for writing the manuscript. Alicia Huerta was an employee of GlaxoSmithKline at the time of the analysis. Henrik Svedsater is an employee of and holds stocks of GlaxoSmithKline.

Open Access This article is distributed under the terms of the Creative Commons Attribution 4.0 International License (http://creativeco mmons.org/licenses/by/4.0/), which permits unrestricted use, distribution, and reproduction in any medium, provided you give appropriate credit to the original author(s) and the source, provide a link to the Creative Commons license, and indicate if changes were made.

\section{References}

1. Global Initiative for Asthma: Global strategy for asthma management and prevention. 2018 GINA report. https://ginasthma. org/2018-gina-report-global-strategy-for-asthma-management -and-prevention. Accessed July 2018

2. European Community Respiratory Health Survey: Variations in the prevalence of respiratory symptoms self-reported asthma attacks, and use of asthma medication in the European Community Respiratory Health Survey (ECRHS). Eur. Respir. J. 9, 687-695 (1996)

3. National Institute of Statistics (INE): Hospital discharges and stays caused by sex and main diagnosis. National results. Hospital morbidity survey 2016. https://www.ine.es/dyngs/INEbase/es/opera cion.htm?c=Estadistica_C\&cid $=1254736176778 \&$ menu $=$ ultiD atos\&idp=1254735573175. Accessed July 2018

4. Martínez-Moratalla, J., Almar, E., Antó, J.M.: Cambios en el tratamiento del asma en la cohorte española del European Community Respiratory Health Survey (ECRHS) en el período 19912001. Perspectiva del tiempo. (Changes in asthma treatment in the Spanish cohort of the European Community Respiratory Health Survey (ECRHS) from 1991-2001: a perspective over time). Arch. Bronconeumol. 49(3), 113-118 (2013). (Spanish)
5. Martínez-Moragón, E., Serra-Batlles, J., De Diego, A., Palop, M., Casan, P., Rubio-Terrés, C., et al.: Coste económico del paciente asmático en España (estudio AsmaCost). (Economic cost of treating the patient with asthma in Spain: the AsmaCost study). Arch. Bronconeumol. 45(10), 481-486 (2009). (Spanish)

6. Ojeda, P., Sanz de Burgoa, V.: Costs associated with workdays lost and utilization of healthcare resources because of asthma in daily clinical practice in Spain. J. Investig. Allergol. Clin. Immunol. 23(4), 234-241 (2013)

7. Demoly, P., Annunziata, K., Gubba, E., Adamek, L.: Repeated crosssectional survey of patient reported asthma control in Europe in the past 5 years. Eur. Respir. Rev. 21, 66-74 (2012)

8. Price, D., Fletcher, M., van der Molen, T.: Asthma control and management in 8,000 European patients: the REcognise Asthma and LInk to Symptoms and Experience (REALISE) survey. NPJ Prim. Care Respir. Med. 24, 14009 (2014)

9. Accordini, S., Corsico, A.G., Braggion, M., Gerbase, M.W., Gislason, D., Gulsvik, A., et al.: The cost of persistent asthma in Europe: an international population-based study in adults. Int. Arch. Allergy Immunol. 160(1), 93-101 (2013)

10. GEMA 4.3: Guía Española para el Manejo del Asma (Spanish guidelines of asthma management). (2018). https://www.gemas ma.com/. Accessed Apr 2018 (Spanish)

11. Woodcock, A., Vestbo, J., Bakerly, N.D., New, J., Gibson, J.M., McCorkindale, S., et al.: Effectiveness of fluticasone furoate plus vilanterol on asthma control in clinical practice: an open-label, parallel group, randomised controlled trial. Lancet 390(10109), 2247-2255 (2017)

12. Weinstein, M.C., O'Brien, B., Hornberger, J., et al.: Principles of good practice for decision analytic modeling in health-care evaluation: report of the ISPOR Task Force on Good Research Practices-modeling studies. Value Health 6(1), 9-17 (2003)

13. Husereau, D., Drummond, M., Petrou, S., et al.: Consolidated health economic evaluation reporting standards (CHEERS) statement. Cost Eff. Resour. Alloc. 11(1), 6 (2013)

14. Lopez-Bastida, J., Oliva, J., Antoñanzas, F., García-Altés, A., Gisbert, R., Mar, J., et al.: Spanish recommendations on economic evaluation of health technologies. Eur. J. Health Econ. 11(5), 513-520 (2010)

15. National Institute of Statistics (INE): Resident population by date, sex and age at January 2017. National results. Detailed series since 2002. http://www.ine.es/dynt3/inebase/es/index.htm?padre $=1894 \&$ capsel $=1895$. Accessed Mar 2018

16. Sobradillo, V., Miravitlles, M., Jimenez, C.A., Gabriel, R., Viejo, J.L., Masa, J.F., et al.: Estudio IBERPOC en España: prevalencia de síntomas respiratorios habituales y de limitación crónica al flujo aéreo. (Epidemiological study of chronic obstructive pulmonary disease in Spain (IBERPOC): prevalence of chronic respiratory symptoms and airflow limitation). Arch. Bronconeumol. 35(4), 156-166 (1999). (Spanish)

17. AsmaMonitor Study: Asthma results 2017. Kantar Health S.A. Spain. http://www.kantarhealth.com. Accessed Mar 2018

18. Clinical Study Report HZA115150: A 12-month, open label, randomised, effectiveness study to evaluate fluticasone furoate (FF, GW685698)/vilanterol (VI, GW642444) inhalation powder delivered once daily via a novel dry powder inhaler compared with usual maintenance therapy in subjects with asthma. https:// www.gsk-clinicalstudyregister.com/study/115150?search=study \&study_ids $=115150 \#$ csr. Accessed Mar 2018

19. Doz, M., Chouaid, C., Com-Ruelle, L., Calvo, E., Brosa, M., Robert, J., et al.: The association between asthma control, health care costs, and quality of life in France and Spain. BMC Pulm. Med. 13, 15 (2013) 
20. National Institute of Statistics (INE): General Consumer Price Index (IPC). National results. http://www.ine.es/dynt3/inebase/ es/index.htm?padre $=3470 \&$ capsel=3466. Accessed Mar 2018

21. Ministry of Health, Equality and Social Policy: Catalogue of sanitarian products included in the Spanish national Health System pharmaceutical provision (Spanish). https://www.mscbs.gob.es/ profesionales/nomenclator.do. Accessed Apr 2018

22. López-Viña, A., Giner, J., Molina, J., Palicio, J., Plaza, J., Quintano, J.A., et al.: Multidisciplinary consensus on the nonadherence to clinical management of inhaled therapy in Spanish asthmatic patients. Clin. Ther. 39(8), 1730-1745 (2017)

23. Rolnick, S.J., Pawloski, P.A., Hedblom, B.D., Asche, S.E., Bruzek, R.J.: Patient characteristics associated with medication adherence. Clin. Med. Res. 11(2), 54-65 (2013)

24. Cisneros, C., Quiralte, J., Capel, M., Casa, M.A., Mellstrom, C.: Análisis coste-efectividad de budesonida/formoterol en el tratamiento de mantenimiento y a demanda (Symbicort SMART $\left.{ }^{\circledR}\right)$ frente a salmeterol/fluticasona más terbutalina, en el tratamiento del asma persistente en España. Pharmacoecon. Span. Res. Artic. 7(4), 163-175 (2010). (Spanish)

25. Collados, C., Martín, V., González-Torralba, F., Rejas, J.: Análisis coste-efectividad de beclometasona/formoterol frente a fluticasona/salmeterol en el tratamiento de pacientes con asma moderada a grave en España. Pharmacoecon. Span. Res. Artic. 12, 53-62 (2015). (Spanish)
26. Martínez-Moragón, E., Delgado, J., Ojeda, P., Pérez Del Llano, L., Antón, C., Martín, C., et al.: Economic evaluation of fluticasone propionate/formoterol (Flutiform ${ }^{\circledR}$ ) vs. fluticasone/salmeterol and budesonide/formoterol in Spain. Pulm. Ther. 2(2), 199-213 (2016)

27. Vallejo-Aparicio, L., Peces-Barba, G., Gil, A., Huerta, A.: Costconsequence analysis of fluticasone furoate/vilanterol $92722 \mathrm{mcg}$ for the management of COPD in the Spanish NHS. Clinicoecon. Outcomes Res. 10, 501-510 (2018)

28. Haldar, P., Pavord, I.D., Shaw, D.E., Berry, M.A., Thomas, M., Brighling, C.E., et al.: Cluster analysis and clinical asthma phenotypes. Am. J. Respir. Crit. Care Med. 178, 218-224 (2008)

29. Hermosa, J.L., Sanchez, C.B., Rubio, M.C., Minguez, M.M., Walther, J.L.: Factors associated with the control of severe asthma. J. Asthma 47(2), 124-130 (2010)

30. Sicras-Mainar, A., Huerta, A., Sanchez, D., Navarro-Artieda, R.: Uso de recursos y costes asociados a la no adherencia al tratamiento con corticoides inhalados en el asma. [Use of resources and costs associated with non-adherence to inhaled corticosteroid treatment in asthma]. Semergen 44(1), 13-22 (2018). (Spanish)

Publisher's Note Springer Nature remains neutral with regard to jurisdictional claims in published maps and institutional affiliations. 